\title{
Comparative clinical study of the effectiveness of different dental bleaching methods - two year follow-up
}

\author{
Rafael Francisco Lia MONDELLI ${ }^{1}$, Juliana Felipi David e Góes de AZEVEDO² ${ }^{2}$ Ana Carolina FRANCISCONI ${ }^{3}$, Cristiane \\ Machado de ALMEIDA ${ }^{4}$, Sérgio Kiyoshi ISHIKIRIAMA ${ }^{5}$
}

\author{
1- DDS, MS, PhD, Associate Professor, Department of Restorative Dentistry, Endodontics and Dental Materials, Bauru School of Dentistry, University of São \\ Paulo, São Paulo, Brazil. \\ 2- PhD student, Department of Restorative Dentistry, Endodontics and Dental Materials, Bauru School of Dentistry, University of São Paulo, São Paulo, Brazil. \\ 3- DDS, PhD, Bauru School of Dentistry, University of São Paulo, São Paulo, Brazil. \\ 4- DDS, PhD, Bauru School of Dentistry, University of São Paulo, São Paulo, Brazil. \\ 5- DDS, MS, PhD, Assistant Professor, Department of Restorative Dentistry, Endodontics and Dental Materials, Bauru School of Dentistry, University of São \\ Paulo, São Paulo, Brazil.
}

Corresponding address: Rafael Francisco Lia Mondelli - Al. Dr. Octávio Pinheiro Brisolla, 9-75 - Bauru - SP - $17012-901$ - C.P. 73 - Departamento de Dentística, Endodontia e Materiais Dentários - Faculdade de Odontologia de Bauru, Universidade de São Paulo - Phone: 55 14 $3235-8265$ - e-mail: rafamond@fob.usp.br

Received: October 13, 2010 - Modification: March 12, 2011 - Accepted: June 08, 2011

\section{ABSTRACT}

\begin{abstract}
This study evaluated color change, stability, and tooth sensitivity in patients submitted to different bleaching techniques. Material and methods: In this study, 48 patients were divided into five groups. A half-mouth design was conducted to compare two in-office bleaching techniques (with and without light activation): G1: 35\% hydrogen peroxide (HP) (Lase Peroxide - DMC Equipments, São Carlos, SP, Brazil) + hybrid light (HL) (LED/Diode Laser, Whitening Lase II DMC Equipments, São Carlos, SP, Brazil); G2: 35\% HP; G3: 38\% HP (X-traBoost - Ultradent, South Jordan UT, USA) + HL; G4: 38\% HP; and G5: 15\% carbamide peroxide (CP) (Opalescence PF - Ultradent, South Jordan UT, USA). For G1 and G3, HP was applied on the enamel surface for 3 consecutive applications activated by HL. Each application included 3×3' HL activations with $1^{\prime}$ between each interval; for G2 and G4, HP was applied 3x15' with 15' between intervals; and for G5, 15\% CP was applied for 120 '/10 days at home. A spectrophotometer was used to measure color change before the treatment and after 24 h, 1 week, 1, 6, 12, 18 and 24 months. A VAS questionnaire was used to evaluate tooth sensitivity before the treatment, immediately following treatment, $24 \mathrm{~h}$ after and finally 1 week after. Results: Statistical analysis did not reveal any significant differences between in-office bleaching with or without HL activation related to effectiveness; nevertheless the time required was less with HL. Statistical differences were observed between the results after $24 \mathrm{~h}, 1$ week and 1, 6, 12, 18 and 24 months (intergroup). Immediately, in-office bleaching increased tooth sensitivity. The groups activated with HL required less application time with gel. Conclusion: All techniques and bleaching agents used were effective and demonstrated similar behaviors.
\end{abstract}

Key words: Dental bleaching. Dentin sensitivity. Hydrogen peroxide.

\section{INTRODUCTION}

Tooth color is determined by a combination of the different optical properties of enamel, dentin and pulp ${ }^{15}$. Tooth discolorations vary in etiology, appearance, localization, severity and adherence to tooth structure, and they are categorized as intrinsic or extrinsic. Although extrinsic discoloration can be removed with a prophylactic cleaning procedure, intrinsic staining necessitates chemical bleaching. Bleaching has been accepted as the least aggressive method for treating discolored teeth.

Until recently, the most commonly used method for vital teeth was home bleaching, originally proposed by Haywood and Heymann ${ }^{14}$ (1989), in which an individual tray that contained $10 \%$ 
carbamide peroxide was used by the patient during the night for approximately 2 to 5 weeks. This technique presents a number of advantages such as easy application, less peroxide concentration, lower cost and less time in the dental office ${ }^{2,13}$. However, it also presents some disadvantages, especially because of the professional's lack of control over monitoring the use of the bleaching agents and trays by the patients. In addition, some patients did not adjust to the trays, a weekly visit is necessary to observe any initial bleaching results, and 2 to 5 weeks are required to obtain the desired results.

With the hope of obtaining more control, color stability, and effectiveness, as well as to save time, in-office bleaching was proposed. This technique utilizes high concentrations of hydrogen peroxide (between $15 \%$ and $38 \%$ ) that can be activated by light sources or heat. The equipment can use different light sources, such as halogen, Plasma arc, light emitting diode (LED), ultraviolet lamp, laser (Argon, Diode, Neodymium-YAG or $\mathrm{CO}_{2}$ ) and hybrid light $3,18,20,22,24,25,30$.

Tooth discoloration and bleaching assessments/ measurements can range from subjective comparison methods to the use of objective instrumentation. There are limitations to the use of subjective measurement methods using porcelain or acrylic resin shade guides; these include the effectiveness of variables such as light conditions, experiences, age, fatigue of the human eye, and conditions such as color blindness ${ }^{28}$.

This CIELAB system was defined in 1967 by the International Commission on Illumination ${ }^{9}$. This is a three-dimensional uniform color space with equal distances corresponding to equally perceived color differences. This system has three axes: the $L^{*}$ axis represents lightness and extends from 0 (black) to 100 (white); and a* and b* represent the redness-greenness and yellowness-blueness axis, respectively. When $a *$ and $b^{*}$ coordinates approach zero, the colors become neutral. A color difference $(\triangle E)$ between two objects can be calculated within the CIELAB color system. The spectrophotometer was considered more reliable by Matis, et al. ${ }^{19}$ (2002) because this method is more objective and sensible than a visual scale and photos. Many authors have used this evaluation system as it allows for a better comparison of the results obtained $3,17,18,22,26,29$.

Tooth sensitivity during the bleaching period, at home or in office, is described as the biggest problem for some authors, but sensitivity can disappear before bleaching ends $2,3,13,20,21,24$. Other effects, such as small changes in the enamel structure after bleaching treatments, have also raised concerns for some researchers. These alterations can be easily restored by polishing, and enamel contact with calcium and phosphate present in the saliva ${ }^{1}$, as well as the application of fluoride ${ }^{4}$. Changes in the micro-hardness, morphology, roughness, and wear are considered insignificant to many authors $6,13,21$.

Many studies have evaluated the effectiveness and security of some new products and techniques. However, there is no consensus in relation to the effectiveness of at-home or in-office bleaching, nor about their effects on the dental tissues ${ }^{2,25}$. The activation of a bleaching agent by the thermocatalytic technique has been questioned due to its deleterious effects on the structure. The objective of this randomized clinical study was to evaluate tooth sensitivity, the degree of the color alteration $(\Delta \mathrm{E})$ and bleaching maintenance after 2 years, and to compare the effectiveness of the at-home and in-office bleaching techniques, with and without the use of hybrid light source for gel activation.

\section{MATERIAL AND METHODS}

\section{Patient inclusion and exclusion criteria}

This research was approved by the Ethics Committee in Research of the Bauru School of Dentistry, University of São Paulo (process: 29/2006). Forty-eight patients were selected using the following inclusion criteria: needed to have all anterior teeth (superior and inferior) without restorations or caries; to agree to sign the consent form; 18 to 30 years old; in good health; color $\mathrm{A} 3$ in at least four teeth; and to agree to return for scheduled visits and follow-up examinations. The exclusion criteria were: any disease that can interfere in the research; gingivitis or periodontitis; those who smoke; any reaction to peroxides; any family history of neoplasia in the oropharinge and adjacency; use of any bleaching agents within the last year; tooth sensitivity of less than 1 on the VAS questioner scale; pregnant or lactating women; and tetracycline stained teeth.

\section{Study design}

The 48 patients selected were randomly divided into 5 groups $(n=16)$, and all bleaching gels were used according to the manufacturer's instructions and are described in Figure 1. For a direct comparison between bleaching protocols employed, a split-mouth design was used, where the same patients were submitted to two bleaching treatments, one on the right superior and inferior arcs and the other in the left superior and inferior $\operatorname{arcs}(\mathrm{G} 1$ and $\mathrm{G} 2$; $\mathrm{G} 3$ and $\mathrm{G} 4$ ). The hybrid light (HL), Whitening Laser II (LED/therapeutic diode laser) - (DMC Equipments, São Carlos, SP, Brazil), was used and employed 6 LEDs each with a wavelength of $470 \mathrm{~nm}$ and irradiance of $350 \mathrm{~mW} / \mathrm{cm}^{2}$, and 3 infrared diode laser points each with a wavelength 
of $810 \mathrm{~nm}$ and $200 \mathrm{~mW} / \mathrm{cm}^{2}$.

For Groups 1, 2, 3 and 4, the clinical steps were done in office, with and without light activation:

Supra-gingival prophylaxis using pumice stone and a "Robson" brush was performed, followed by color measurement (canines, central and lateral incisors, superior and inferior arcs) with a spectrophotometer and the initial photo using a digital camera (D-70, Nikon) (Figure 2).

Application in the superior and inferior arcs of a gingival barrier (Lase-Protect, DMC Equipments, São Carlos, SP, Brazil) in Groups 1 and 2 and an OpalDam (Ultradent Products Inc., South Jordan UT, USA) in Groups 3 and 4 was followed by photoactivation.

In Group 1, the superior and inferior teeth on the right side received an application of a $1 \mathrm{~mm}$ thick bleaching gel composed of 35\% HP (Figure $3 \mathrm{~A})$, and the left side was protected with gauze. Next, the bleaching gel was activated with $\mathrm{HL}$ for $3^{\prime}$ in both arcs simultaneously (Figure 3B), followed by a $1^{\prime}$ wait to allow the temperature to fall. This step was performed twice more consecutively. After the removal of the gel and teeth cleansing, the procedure was repeated two more times in the same appointment for a total $33^{\prime}$ of gel action. After the completion of the right side arcs, the bleaching gel (HP 35\%) without HL activation (Group 2) was applied to the left side arcs for 3 consecutive 15' periods, with $15^{\prime}$ intervals between each application, totaling $45^{\prime}$ of gel action. In Groups 3 and 4, the bleaching gel (HP 38\%) was applied and followed the same activation protocols as Groups 1 and 2 (right side activated with $\mathrm{HL}$ and left side without), respectively.

Polishing of the teeth in the vestibular faces was performed on all groups with a felt disc impregnated with abrasives (Laser Peroxide, DMC Equipments, São Carlos, SP, Brazil) to reestablish the enamel smoothness. After polishing, a desensitizing gel (Lase Sensy, DMC Equipments, São Carlos, SP, Brazil) composed of $2 \%$ sodium fluoride and $5 \%$ potassium nitrate was applied for 4 '. For the groups activated with $\mathrm{HL}$, laser therapy was performed (25 J for 30") on all patients, regardless of tooth sensitivity, in order to avoid and control postoperative sensitivity.

For Group 5 (home bleaching), after initial photos were taken and color measurements were done, the individual trays for the superior and inferior arcs were given to each patient, as well as four gel-filled syringes (CP 15\%) and instructions for use. The gel was to be used 2 hours per day over a period of 10 days. During this period, patients were not to use any products that could compromise the bleaching.

In the present study, Group 5 (home bleaching) was employed only to compare with the results of in-office bleaching, with and without light activation. It is important to know that in all groups, the control was obtained in the baseline color measurement of each tooth that was evaluated from each patient.

\begin{tabular}{|c|c|c|c|}
\hline Comercial brands & Bleaching gels & Manufacturer & Clinical use \\
\hline $\begin{array}{l}\text { Opalescence PF } \\
\text { (CP 15\%) }\end{array}$ & $\begin{array}{c}\text { Carbamine Peroxide } \\
\qquad 15 \%\end{array}$ & $\begin{array}{l}\text { Ultradent } \\
\text { Products Inc. }\end{array}$ & Home bleaching \\
\hline $\begin{array}{l}\text { Opalescence } \\
\text { Xtra Boost } \\
\text { (HP 38\%) }\end{array}$ & $\begin{array}{c}\text { Hydrogen Peroxide } \\
38 \%\end{array}$ & $\begin{array}{c}\text { Ultradent } \\
\text { Products Inc. }\end{array}$ & $\begin{array}{l}\text { In office with chemical } \\
\text { and/or physical } \\
\text { activation }\end{array}$ \\
\hline $\begin{array}{l}\text { Laser Peroxide } \\
\qquad(\mathrm{HP} 35 \%)\end{array}$ & $\begin{array}{c}\text { Hydrogen Peroxide } \\
35 \%\end{array}$ & $\begin{array}{l}\text { DMC Equipaments } \\
\text { Ltda }\end{array}$ & $\begin{array}{l}\text { In office with chemical } \\
\text { and/or physical activation }\end{array}$ \\
\hline
\end{tabular}

Figure 1- Bleaching gels used
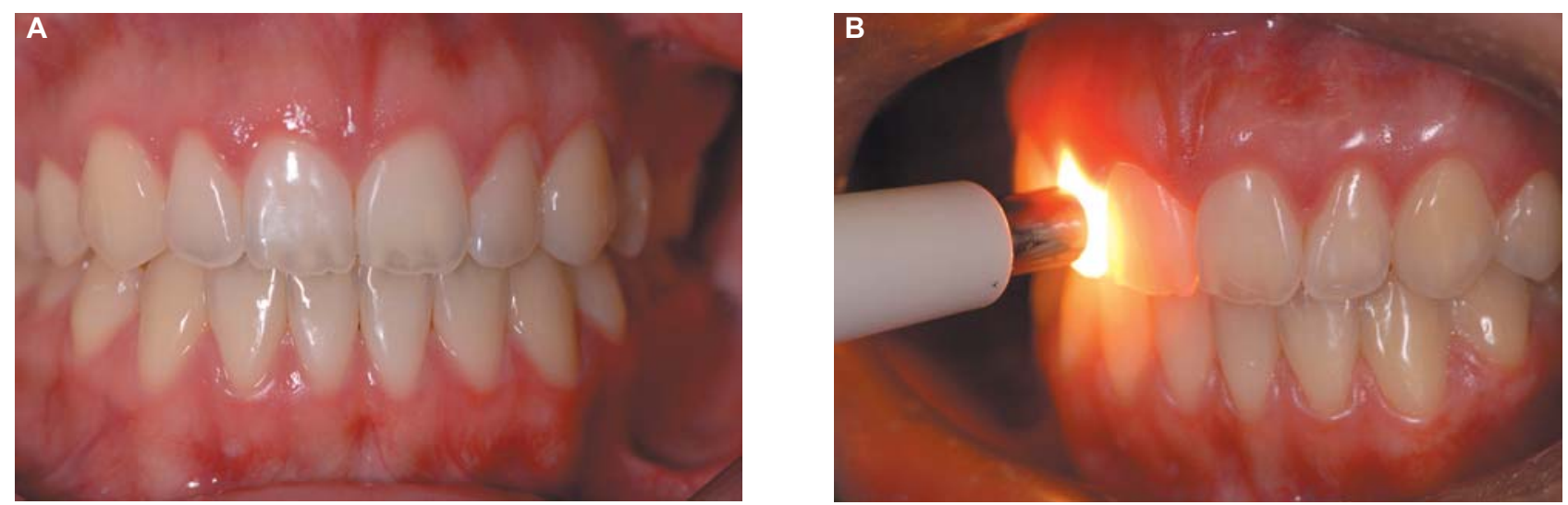

Figure 2- (A) Initial photo and (B) spectrophotometer color measurement 
All patients received instructions to avoid any substance that could stain teeth in the first 48 hours following the treatment, e.g., coffee, black tea, cola, mustard, ketchup, red wine, soy sauce, chocolate, red fruits, tomato sauce, beets, etc. Beyond these, patients were instructed to avoid other substances that could stain teeth such as red lipstick, consumption of tobacco products, and food and beverages with acidic $\mathrm{pH}$ levels. For patients who experienced exacerbated tooth sensitivity (Groups 1, 2, 3 and 4), an anti-inflammatory (Nimesulida 100 mg EMS, Eurofarma, Medley, Novartis) was prescribed for one or two days.

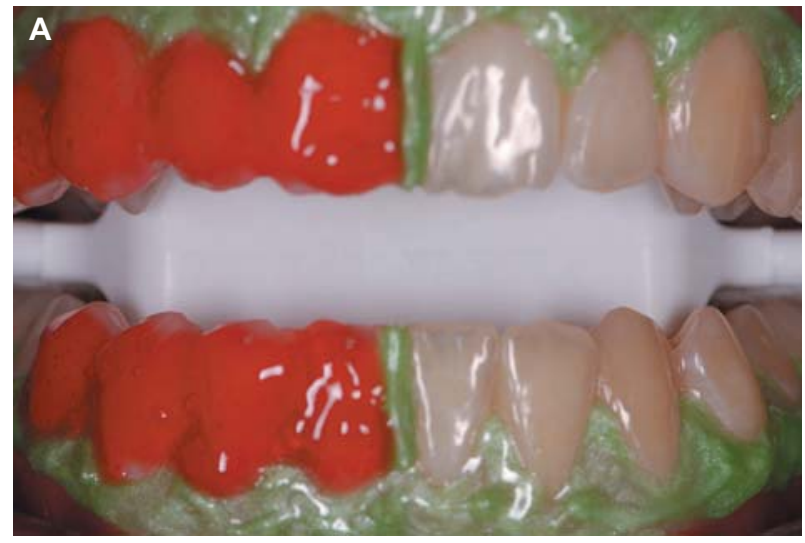

Instrumental method for color measurement

Digital photos were taken and instrumental color monitoring was performed before bleaching and 24 hours, 1 week, 1 month, 6 months, 12 months, 18 months and 24 months after (Figure 4), using a contact-type intra-oral spectrophotometer (Vita Easyshade, Vita-Zanhnfabrik, Bad Säckingen, Germany). Color differences were calculated using the following equation: $\Delta \mathrm{E}=\left[\left(\Delta \mathrm{L}^{*}\right)^{2}+\left(\Delta \mathrm{a}^{*}\right)^{2}+\left(\Delta \mathrm{b}^{*}\right)^{2}\right]^{1 / 2}$ 9 .

The measurements to obtain tooth color were done using a spectrophotometer following the manufacturer's instructions and in agreement with Kim-Pusateri, et al. ${ }^{16}$ (2009); these measurements

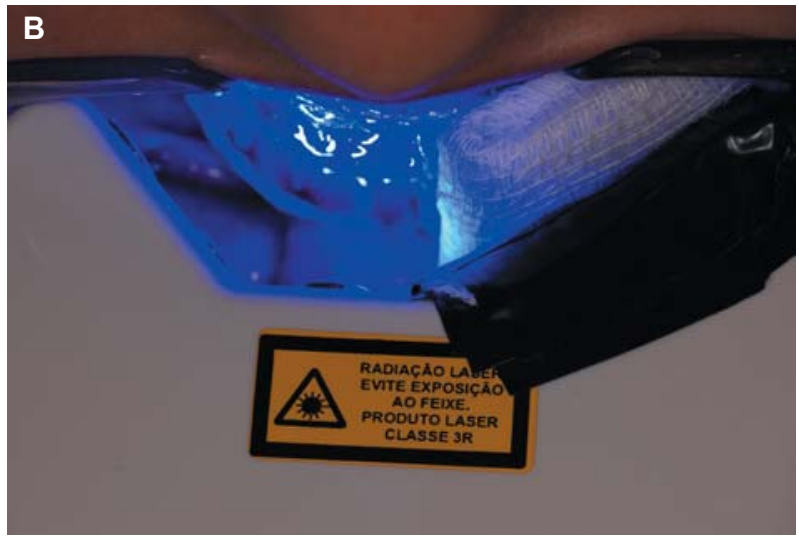

Figure 3- Clinical bleaching procedure in groups 1 and 2: A- bleaching gel application in the right side arcs; B- activation of the gel with hibrid light $(\mathrm{HL})$ in the right side arcs and protection of the left side arcs
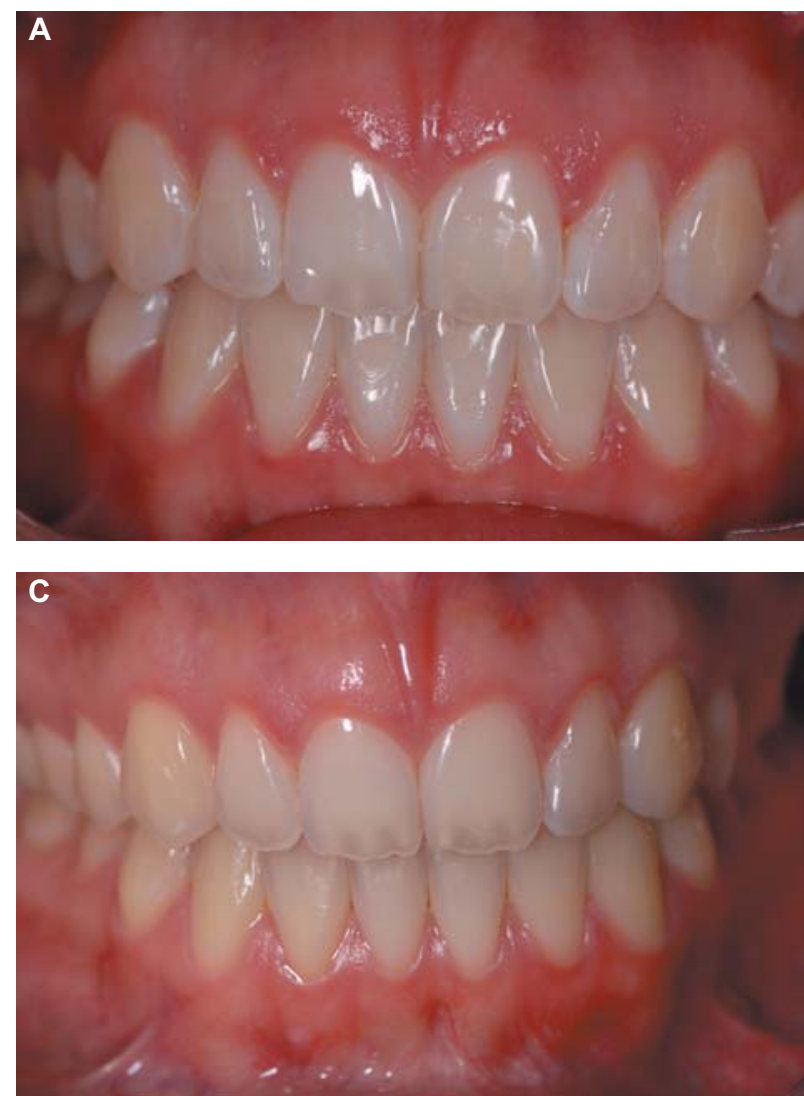
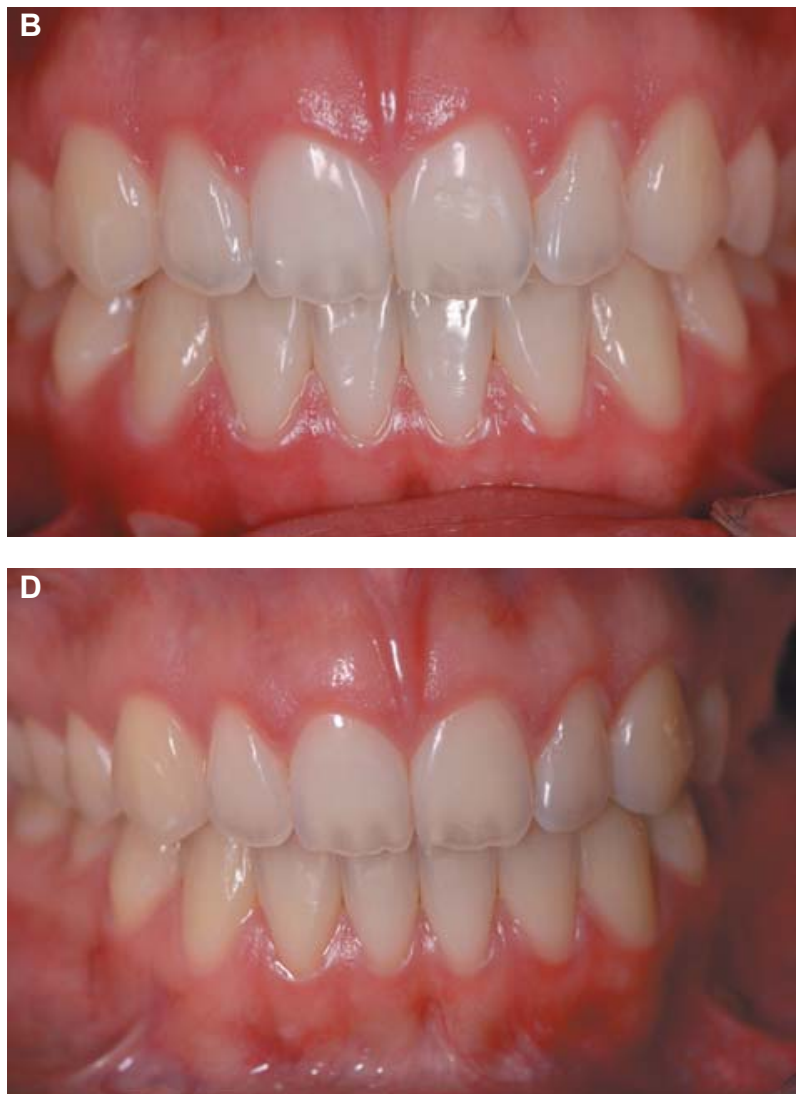

Figure 4- Control after: (A) 24 hours; (B) 1 month; (C) 12 months; (D) 24 months 
were taken from the same area of each tooth (middle of the tooth) two times consecutively. When these values were equal, they were registered. When the values were not equal, additional measurements were taken until equal measurements were obtained, and only one measurement for each tooth was recorded.

\section{Tooth sensitivity assessment}

Before bleaching, the patients were submitted to the VAS questionnaire to measure tooth sensitivity (baseline), as well as immediately after bleaching, 24 hours and 1 week. This evaluation determined the differences between the evaluation periods and the bleaching gels tested. The patient was to indicate any tooth or oral sensitivity by marking the level of sensitivity on the horizontal line, which ranges from 0 to 10 , with 10 being the most sensitive.

Range of sensitivity scores used:

$0-1$ : No pain

2-3: Mild pain

4-6: Moderate pain

7-8: Severe pain

9-10: Intolerable pain

\section{Statistical analysis}

All groups were submitted to histogram and Kolmogerov-Smirnov tests, and all data presented normal distribution criteria. As a result of this normal distribution, the results were submitted to
ANOVA tests to identify any differences between groups $(p \leq 0.05 \%)$ and Tukey tests for individual comparisons between all groups with a level of significance of $\mathrm{p} \leq 0.05 \%$.

\section{RESULTS}

The number of subjects who returned for each evaluation period for all groups evaluated $(n=16)$ can be observed in Figure 5.

The values of the degree of change and color maintenance $(\Delta \mathrm{E})$ in the in-office and at-home bleaching techniques over 24 months were submitted to ANOVA testing by three-way ANOVA (bleaching agents, photoactivation and time), and Group 5 was submitted to two-way ANOVA (time and bleaching gel). No statistically significant differences were observed between in-office bleaching treatments (G1, G2, G3, and G4). The home bleaching group (G5) presented statistically higher values of $\Delta \mathrm{E}$ in comparison to the other two bleaching agents used in office with or without $\mathrm{HL}$ (G1, G2, G3 and G4) (Table 1; Figure 6).

The observation time (intra-groups) presented statistically significant differences in the five periods for all groups evaluated (Tukey test, $\mathrm{p} \leq 0.05$ ).

The differences in degree of sensitivity were determined using two-way ANOVA testing (bleaching agent and time evaluation) and the Tukey test for individual comparisons (Table 2). Statistical differences were observed only in the

\begin{tabular}{|c|c|c|c|c|c|c|c|c|}
\hline Groups & Initial & 24 hours & $\mathbf{1}$ week & $\mathbf{1}$ month & $\mathbf{6}$ months & $\mathbf{1 2}$ months & $\mathbf{1 8}$ months & $\mathbf{2 4}$ months \\
\hline 1 & 16 & 16 & 15 & 16 & 15 & 14 & 11 & 11 \\
\hline 2 & 16 & 16 & 15 & 16 & 15 & 14 & 11 & 11 \\
\hline 3 & 16 & 16 & 16 & 15 & 14 & 14 & 11 & 10 \\
\hline 4 & 16 & 16 & 16 & 15 & 14 & 14 & 11 & 10 \\
\hline 5 & 16 & 16 & 13 & 13 & 12 & 12 & 9 & 8 \\
\hline
\end{tabular}

Figure 5- Distribution of the number of subjects that returned for each evaluation period for all groups evaluated $(n=16)$

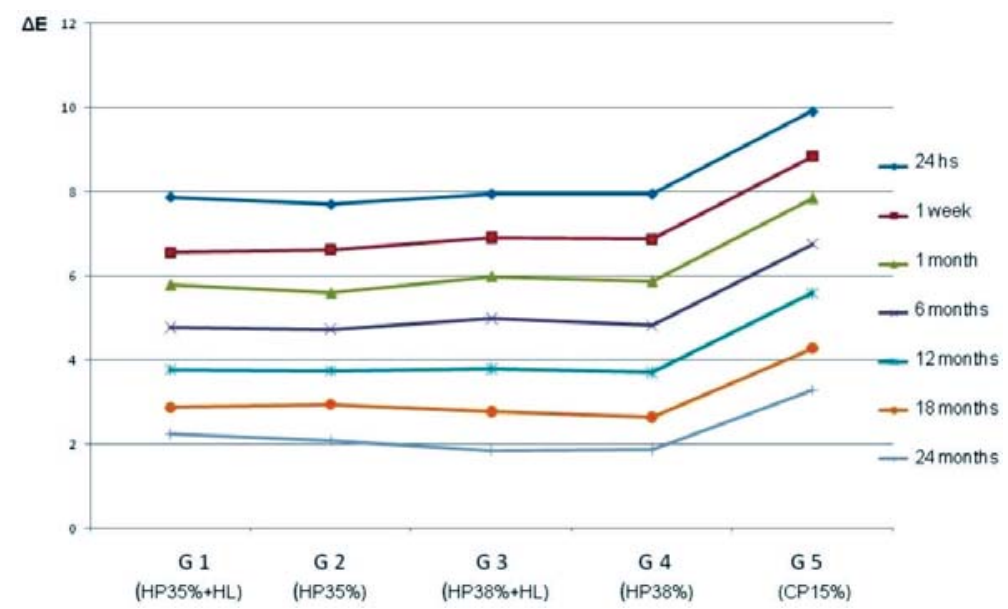

Figure 6- Graph of mean $(\Delta \mathrm{E})$ for bleaching groups evaluated during 24 months 
Table 1- Mean and standart deviation of $\Delta \mathrm{E}$ for bleaching groups evaluated during 24 months

\begin{tabular}{|c|c|c|c|c|c|c|c|}
\hline Groups & 24 hours & 1 week & 1 month & 6 month & 12 months & 18 months & 24 months \\
\hline & (mean $\pm S D)$ & (mean $\pm S D)$ & (mean $\pm S D)$ & (mean $\pm S D)$ & (mean $\pm S D)$ & (mean $\pm S D)$ & (mean $\pm S D)$ \\
\hline G1: & $7.80+1.42^{\mathrm{Ba}}$ & $6.45+1.40^{\mathrm{Bb}}$ & $5.64+1.45^{\mathrm{Bc}}$ & $4.49+1.45^{\mathrm{Bd}}$ & $2.99+1.45^{\mathrm{Be}}$ & $2.87+0,67^{\mathrm{Bf}}$ & $2.23+0.61^{\mathrm{Bg}}$ \\
\hline \multicolumn{8}{|l|}{$\mathrm{HP} 35 \%+\mathrm{HL}$} \\
\hline G2: & $7.49+1.45^{\mathrm{Ba}}$ & $6.54+1.37^{\mathrm{Bb}}$ & $5.43+1.47^{\mathrm{Bc}}$ & $4.33+1.39^{\mathrm{Bd}}$ & $2.85+1.41^{\mathrm{Be}}$ & $2.94+0.68^{\mathrm{Bf}}$ & $2.09+0.69^{\mathrm{Bg}}$ \\
\hline \multicolumn{8}{|l|}{ HP $35 \%$} \\
\hline G3: & $7.83+1.39^{\mathrm{Ba}}$ & $6.77+1.32^{\mathrm{Bb}}$ & $5.78+1.37^{\mathrm{BC}}$ & $4.64+1.26^{\mathrm{Bd}}$ & $2.75+1.15^{\mathrm{Be}}$ & $2.77+0.60^{\mathrm{Bf}}$ & $1.85+0.56^{\mathrm{Bg}}$ \\
\hline \multicolumn{8}{|l|}{$\mathrm{HP} 38 \%+\mathrm{HL}$} \\
\hline G4: & $7.76+1.50^{\mathrm{Ba}}$ & $6.67+1.56^{\mathrm{Bb}}$ & $5.64+1.38^{\mathrm{Bc}}$ & $4.42+1.47^{\mathrm{Bd}}$ & $2.75+1.26^{\mathrm{Be}}$ & $2.63+0.64^{\mathrm{Bf}}$ & $1.87+0.60^{\mathrm{Bg}}$ \\
\hline \multicolumn{8}{|l|}{ HP $38 \%$} \\
\hline G5: & $9.80+1.75^{\mathrm{Aa}}$ & $8.70+1.64^{\mathrm{Ab}}$ & $7.67+1.57^{\mathrm{AC}}$ & $6.52+1.62^{\mathrm{Ad}}$ & $5.07+1.63^{\mathrm{Ae}}$ & $4.27+0.98^{\mathrm{Bf}}$ & $3.29+0.78^{\mathrm{Bg}}$ \\
\hline $\mathrm{CP} 15 \%+\mathrm{HL}$ & & & & & & & \\
\hline
\end{tabular}

* Lower case letters: analysis between columns in the same line

* Capital letters: analysis between lines in the same column $\mathrm{HL}=$ hibrid light

Table 2- Description of the sensitivity results based on the bleaching gel used

\begin{tabular}{|c|c|c|c|c|}
\hline Bleaching gels & Baseline & Immediately after bleaching & 24 hours & 7 days \\
\hline & (mean $\pm S D)$ & (mean $\pm S D)$ & (mean $\pm S D)$ & (mean $\pm S D)$ \\
\hline HP $35 \%$ & $0.45+0.88^{A}$ & $5.47+3.13^{B}$ & $0.93+0.90^{\mathrm{D}}$ & $0.42+0.87^{E}$ \\
\hline HP $38 \%$ & $0.71+0.83^{A}$ & $3.95+1.78^{\mathrm{BC}}$ & $1.89+2.33^{D}$ & $0.69+0.82^{\mathrm{E}}$ \\
\hline CP $15 \%$ & $0.65+0.73^{A}$ & $2.54+1.91^{\mathrm{C}}$ & - & $0.72+0.68^{\mathrm{E}}$ \\
\hline
\end{tabular}

*Capital letters: analysis between lines in the same column

period immediately after the bleaching between $\mathrm{PH} 35 \%$ and PC 15\%. After 24 hours, there were no differences between in-office bleaching gels, and after 1 week, the sensitivity levels returned to normal.

\section{DISCUSSION}

The purpose of this in vivo study about vital tooth bleaching was to compare the effectiveness and stability in-office (with or without photoactivation) and at-home bleaching techniques in relation to color change $(\Delta E)$ and tooth sensitivity, for 24 months after the treatments. CP $15 \%$ gel was used at home and in office, two bleaching agents with high concentrations (HP 35 and 38\%) were used for chemical and physical activation.

Tooth color alteration can be determined by means of a visual evaluation using a color shade, which is a subjective method, very functional, easy and fast to use $^{25}$. Objective methods that can be employed are the use of a spectrophotometer, colorimeters and software images ${ }^{15}$. The instrumental evaluation has been preferred over the visual evaluation because it makes the process more practical and statistically more reliable ${ }^{19}$. For Groups 1, 2, 3 and 4 (in-office bleaching), six teeth were evaluated from each patient, and for Group 5, twelve teeth; this allowed measurements from each patient to become more precise in obtaining the color alteration $(\Delta E)$ in numeric values (CIELAB System) and provided normal distribution results. This is another advantage of this method (spectrophotometer) in comparison to a visual scale evaluation by operators. In a study done by Kim-Pusateri, et al. ${ }^{16}$ (2009), using the same methods, they confirmed that this method gives more confidence and standard results, with $96 \%$ accuracy.

Tooth bleaching is directly related to tooth structure and permeability ${ }^{25}$. The enamel behaves like a semi-permeable membrane that possibly transmits water and other substances with small molecular size, such as oxygen ions ( $\mathrm{O}^{-}$) present in the HP. These characteristics allow oxygen diffusion (oxygen reaction) over the organic structure of teeth and permit reaction to the stained molecules, and this promotes the bleaching ${ }^{13}$. A light source was used with the objective to accelerate the reaction and become more effective $e^{1,7,20,22,26,30}$. The theoretical advantage of the light source is the increase in the hydrogen peroxide temperature, thus accelerating the reaction and forming hydroxyl 
and oxygen free radicals ${ }^{1,26,30}$. A temperature rise of $10^{\circ} \mathrm{C}$ increases the speed of hydrogen peroxide decomposition by 2.2 times $^{12}$. To increase the interaction of visible light with the bleaching gel, manufacturers incorporate coloring agents or pigments into their products, which have colors capable of promoting maximum absorption of this light and subsequent conversion into heat.

For the present study, one hybrid light source composed of a LED and a therapeutic diode laser were used to activate the bleaching gel in the inoffice techniques. In accordance with Camargo, et al. ${ }^{7}$ (2009), the use of a LED or Nd:Yag laser for activation of the HP 35\% permitted a higher degree of penetration in the direction of the chamber pulp (20 minutes after the gel application), in comparison to the groups without photo activation.

Post-bleaching sensitivity differs from dentin hypersensitivity because it is related directly to the penetration of the sub-products of the bleaching gels in the dentin and pulp tissue, through the enamel, causing reversible pulpit and consequent teeth thermal sensitivity, but not causing permanent damage to the pulp ${ }^{23}$. These responses are correlated with the peroxide concentration, time, frequency of gel application and pulp temperature rise with light activation ${ }^{2,13,19,24}$. Carrasco, Carrasco-Guerisoli and Fröner ${ }^{8}$ (2008), in an in vitro study, found low indexes of temperature increases considered compatible with pulp vitality maintenance, when applying an LED source or HL to the gel (35\% HP). Coutinho, et al. ${ }^{10}$ (2008) evaluated the rise of pulp-chamber temperature induced by different light sources in in-office bleaching with HP 35\%, and they concluded that the specific combination of color agent + light color determines good dental bleaching with a smaller temperature increase and, consequently, less sensitivity. In the present study, the lowest dental sensitive index was observed in the G5 (home bleaching) in the function of low gel concentration (CP 15\%). Groups 1-4 used high concentrations of the bleaching gel (HP 35 and $38 \%$ ), and all experienced higher levels of sensitivity. After 24 hours, the degree of sensitivity had lowered considerably and returned to normal levels after one week for all groups evaluated. Although the groups in office were completed in the same appointment, to each patient (right and left side), it was not possible to determine whether the teeth with or without $\mathrm{HL}$ activation presented higher or lower degrees of sensitivity. As a result, sensitivity analysis was determined just by the bleaching agent (Table 2). Marson, et al.18 (2008), in an in vivo study, found high levels of sensitivity ( $92 \%$ of patients) in in-office bleaching using HP $35 \%$ with and without any light source, but in all cases, this sensitivity disappeared 24 hours after the treatment.
The use of $\mathrm{HL}$ in one in vitro study of rats found a less inflammatory response in the coronal pulp independent of the bleaching gel concentration used (HP 15\%, 25\% and 35\%), when compared to the in-office bleaching without $\mathrm{HL}$ activation. This indicated that the diode laser present in the $\mathrm{HL}$ equipment has a therapeutic effect in the process ${ }^{11}$. The initial results (after 1 month) presented by Rosa and Mondelli24 (2009), in a clinical research study comparing the level of sensitivity in inoffice bleaching (HP 35\%) with and without light activation $(\mathrm{HL})$, were obtained by performing the procedure at different times (7 days apart) to the same patient. The group without $\mathrm{HL}$ activation $\left(3 \times 15^{\prime}\right)$ presented, immediately after the bleaching, a significant increase in sensitivity compared to the groups with $\mathrm{HL}\left(3 \times 7^{\prime} 30^{\prime \prime}\right)$. These results (Table 2 ) suggest that the light activation system (LED/ therapeutic laser), with half of the gel action time, produces the same level of color change, but with less pulp inflammation and, consequently, lower sensitivity degree, in agreement with Frigo, et al. ${ }^{11}$ (2009). In the present study, all manufacturers' instructions were followed; it is possible that the diode laser diminished the effects of sensitivity, though it was impossible for all patients to identify differences between the right and left side arches. As a result of this observation, tooth sensitivity was compared between bleaching gels rather than bleaching protocols.

Micro-structure alterations, such as microhardness and roughness, which reverted naturally after 7 to 15 days after bleaching due to the effect of the calcium and phosphate ions present in the saliva ${ }^{15,19,21,26}$, as well as to fluoride applications ${ }^{4}$, are not considered significant. One in vitro study done by Mondelli, et al. ${ }^{21}$ (2009) evaluated roughness and wear, before and after brushing, of bovine enamel submitted to different bleaching protocols (CP 16\%; HP 35\%+HL; HP 35\%+halogen light). There were no significant differences among the groups comparing initial and post-bleaching roughness. After brushing, there were differences between the control group and experimental groups. The home bleaching group (CP 16\%) showed a significant increase in roughness values compared to group HP $35 \%+H L$. Wear was significantly less for the control group compared to the other groups. Bleaching techniques promoted increased bovine enamel surface roughness and wear when submitted to simulated brushing.

Cadenaro, et al. ${ }^{6}$ (2008), demonstrated in an in vivo study with $\mathrm{HP}$ and $\mathrm{CP}$ in high concentrations, after multiple applications, no occurrence of roughness alterations in the enamel superficies. All bleaching gels evaluated in this study possessed one important characteristic, a neutral pH level, because gels with acidic $\mathrm{pH}$ can promote higher 
alterations in the topography of the enamel ${ }^{15}$ and have the potential to induce collateral effects, such as tooth sensitivity and gingival irritation ${ }^{13}$.

The difference in the action time of the bleaching gels (contact with teeth) evaluated in this study explain the statistical differences in initial $\Delta E$ value $\mathrm{G} 5$ in relation to the other groups. These differences disappear after 18 and 24 months of control in relation to other in-office groups (Table 1 ). For G1 and G3 (9' HL activation), the total time of gel action was 33', divided into 3 consecutive applications; for G2 and G4, (without light activation), the total time of gel action was 45', divided into 3 consecutive applications of $15^{\prime}$ each with $15^{\prime}$ between each applications; and for $\mathrm{G} 5$, the total time of tray use ( $15 \%$ CP) was 1,200 '. The rise in the number of in-office bleaching treatments without $\mathrm{HL}$ or the possibility of applying and activating, with $\mathrm{HL}$, the bleaching gel up to five times in the same session ${ }^{20}$ will determine the best results (higher $\Delta \mathrm{E}$ ), in order to compensate for differences in gel action time ${ }^{20,24}$.

A new in-office protocol activated with $\mathrm{HL}$ (the same light used in this study), decreased the action time of the gel to $7^{\prime} 30^{\prime \prime}\left(30^{\prime \prime}+2^{\prime} \mathrm{HL}+30^{\prime \prime}+2^{\prime} \mathrm{HL}+30^{\prime \prime}+2^{\prime} \mathrm{HL}\right)$, possibly to obtain teeth bleaching in only one session, justifying the use of $\mathrm{HL}$ in the in office bleaching ${ }^{20,24}$. This protocol enables the bleaching to be obtained in only one session by performing $5 \mathrm{x}$ gel applications. This finding is in agreement with those of other authors, who observed that the light equipment can be used to shorten the gel application time, and this accelerates the bleaching process $^{17,20,22,24}$.

The efficiency of these lights presented some conflicting results ${ }^{3,15,18}$. Marson, et al. ${ }^{18}$ (2008) discovered no differences in the activation or note with a light source (halogen, LED, and LED/Diode laser) in in-office bleaching, but the authors did not follow the protocols recommended by the manufacturers and did not state the gel activation time. This information was obtained in the original PhD thesis, where the activation time for all light sources was only 20 " per tooth in each of two bleaching appointments. On another clinical study, Bernadon, et al. ${ }^{3}$ (2010), compared the efficiency of at-home bleaching versus in-office bleaching activated with HL (Whitening Lase, DMC Equipments, São Carlos, SP, Brazil); in-office bleaching with and without HL activation; and athome bleaching, versus a combination of at-home and in-office bleaching activated with $\mathrm{HL}$. The authors did not observe differences in the bleaching results, sensitivity and durability in the 6 months between the techniques, and they concluded that light activation is not recommended. The authors did not follow the protocol recommended by the manufacturer of the $\mathrm{HL}$, and instead, they performed two sessions with three gel applications of $15^{\prime}$ each and light activation of $4^{\prime}$.

In the present study, independent of the technique, bleaching gel concentration and activation with or without $\mathrm{HL}$, all protocols employed were effective in promoting teeth bleaching. This finding confirms that the results obtained with the bleaching are not dependent on the technique employed (home bleaching, in-office bleaching with or without light activation). The color change (color rebound) in the bleaching treatments during the time evaluated (24 months) was similar among all groups evaluated without statistically significant differences, a finding that supports the results of a two-year study by Swift, May and Wilderider ${ }^{27}$ (1999). Similar results were found in in vivo studies by Bizhang, et al. ${ }^{5}$ (2009), Marson, et. al. ${ }^{18}$ (2009) and Bernadon, et al. ${ }^{3}$ (2010). Bizhang, et al. ${ }^{5}$ (2009) utilized a colorimeter and concluded that at-home bleaching (CP 10\%) and in-office bleaching (HP $15 \%)$ are equally efficient and patients retained the lightness for 3 months.

Given the results of this study and the literature presented, light activation with $\mathrm{HL}$ can produce effective results with less time for gel action, when compared with at-home bleaching and inoffice bleaching without light activation, and this knowledge can be useful in many clinical situations.

\section{CONCLUSIONS}

Due to the results observed during the evaluated times, we can conclude:

In-office bleaching presented highest sensitivity initially in comparison to at-home home bleaching;

All techniques and bleaching gels used were effective in teeth bleaching;

The in-office bleaching techniques utilizing two bleaching gels, with or without light activation (HL), presented similar results; and

The color change $(\Delta E)$ recorded in the bleaching treatments during the time evaluated was similar among all groups evaluated.

\section{ACKNOWLEDGEMENTS}

State of São Paulo Research Foundation/ FAPESP (2006/02540-9) and Cordination of Higher Education and Graduate Training - Capes.

\section{REFERENCES}

1- Attin T, Manolakis A, Buchalla W, Hannig C. Influence of tea on intrinsic colour of previously bleached enamel. J Oral Rehab. 2003;30:488-94.

2- Berga-Caballero A, Forner-Navarro L, Amengual-Lorenzo J. At-home vital bleaching: a comparison of hydrogen peroxide and carbamide peroxide treatments. Med Oral Patol Oral Cir Bucal. 2006;11:E94-9. 
3- Bernardon JK, Sartori N, Ballarin A, Perdigão J, Lopes GC Baratieri LN. Clinical performance of vital bleaching techniques. Oper Dent. 2010;35:3-10.

4- Bistey T, Nagy IP, Simó A, Hegedus C. In vitro FT-IR study of the effects of hydrogen peroxide on superficial tooth enamel. J Dent. 2007;35:325-30.

5- Bizhang M, Chun YH, Damerau K, Shing P, Raab WH, Zimmer S. Comparative clinical study of the effectiveness of three different bleaching methods. Oper Dent. 2009;34:635-41.

6- Cadenaro M, Breschi L, Nucci C, Antoniolli F, Visintini E, Prati $C$, et al. Effect of two in-office whitening agents on the enamel surface in vivo: a morphological and non-contact profilometric study. Oper Dent. 2008;33:127-34.

7- Camargo SEA, Cardoso PE, Valera MC, Araújo MAM, Kojima AN. Penetration of $35 \%$ hydrogen peroxide into the pulp chamber in bovine teeth after LED or Nd:YAG laser activation. Eur J Esthet Dent. 2009;4:82-8.

8- Carrasco TG, Carrasco-Guerisoli LD, Fröner IC. In vitro study of the pulpchamber temperature rise during light-actived bleaching. J Appl Oral Sci. 2008;16:355-9.

9- Commission Internationale de L'Eclairage. Recommendations on uniform colour spaces, colour terms. Paris: Bureau Central de la CIE; 1978. Publication 15, supplement 2.

10- Coutinho DS, Silveira L Jr, Nicolau RA, Zanin F, Brugnera A Jr. Comparison of temperature increase in vitro human tooth pulp by light sources in the dental whitening process. Laser Med Sci. 2009;24:179-85.

11- Frigo L, Pallota RC, Meneguzzo D, Marcos RL, Penna SC, LopezMartins RAB. Evaluation of the photo-activated dental bleaching effect on dental pulp in an in vivo rat experimental model. $\mathrm{R}$ Dental Press Estet. 2009;6:102-14.

12- Goldstein RE, Garber DA. Complete dental bleaching. Chicago: Quintessence Publishing Co.; 1995.

13- Haywood VB. History, safety, and effectiveness of current bleaching techniques and applications of the nightguard vital bleaching technique. Quintessence Int. 1992;23:471-88.

14- Haywood VB, Heymann HO. Nightguard vital bleaching. Quintessence Int. 1989;20:173-6.

15- Joiner $A$. The bleaching of teeth: a review of the literature. J Dent. 2006;34:412-9.

16- Kim-Pusateri S, Brewer JD, Davis EL, Wee AG. Reliability and accuracy of four dental shade-matching devices. J Prosthet Dent. 2009;101:193-9.
17- Lima DA, Aguiar FHB, Liporoni PCS, Munin E, Ambrosano GMB, Lovadino JR. In vitro evaluation of the effectiveness of bleaching agents activated by different light sources. J Prosth. 2009;18:249-54.

18- Marson FC, Sensi LG, Vieira LCC, Araújo E. Clinical evaluation of in-office dental bleaching treatments with and without the use of light activation sources. Oper Dent. 2008;33:5-22.

19- Matis BA, Hamdan YS, Cochran MA, Eckert GJ, Stropes M. A clinical evaluation of a bleaching agent used with and without reservoirs. Oper Dent. 2002;27:5-11.

20- Mondelli RFL, Almeida CM, Toledo FL, Freitas CA, Ishikiriama SK. Clareação de dentes polpados em consultório com e sem condicionamento ácido prévio de esmalte: relato de caso clínico. R Dental Press Estet. 2009;6:42-51.

21- Mondelli RFL, Azevedo JF, Francisconi PAS, Ishikiriama SK, Mondelli J. Wear and surface roughness of bovine enamel submitted to bleaching. Eur J Esthet Dent. 2009;4:396-403.

22- Ontiveros JC, Paravina RD. Color change of vital teeth exposed to bleaching perfomed with and without supplementary light. J Dent. 2009;37:450-7.

23- Roberts RB. Passive tooth bleaching: the cosmetic revolution. La Mesa: R.B. Roberts; 1991.

24- Rosa RE, Mondelli RFL. Comparação clínica entre clareamento com e sem fotoativação. DMC Journal. 2009;5:14-7.

25- Sulieman M, Addy M, MacDonald E, Rees JS. A safety study in vitro for the effects of an in-office bleaching system on the integrity of enamel. J Dent. 2004;32:581-90.

26- Sulieman M, MacDonald E, Rees JS, Addy M. Comparison of three in-office bleaching systems based on $35 \%$ hydrogen peroxide with different light activators. Am J Dent. 2005;18:194-7.

27- Swift EJ Jr, May KN, Wilder AD Jr, Heymann HO, Bayne SC. Two-year clinical evaluation of tooth whitening using at-home bleaching system. J Esth Dent. 1999;11:36-42.

28- Watts A, Addy $M$. Tooth discolouration and staining: a review of the literature. Br Dental J. 2001;190:309-16.

29- Wetter NU, Barroso MC, Pelino JEP. Dental bleaching efficacy with diode laser and LED irradiation: an in vitro study. Lasers Surg Med. 2004;35:254-8.

30- Wiegand A, Vollmer D, Foitzik M, Attin R, Attin T. Efficacy of different whitening modalities on bovine enamel and dentin. Clin Oral Investig. 2005;9:91-7. 